\title{
Experiences of gender-based violence in women asylum seekers from Honduras, EI Salvador, and Guatemala
}

\author{
Kim A. Baranowski*, Eileen Wang**, Megan R. D'Andrea***, Elizabeth K. \\ Singer****
}

Key points of interest

- Women asylum seekers from Honduras, El Salvador, and Guatemala report systemic gender-based violence in their countries of origin.

- These experiences of violence are associated with significant physical and psychological sequelae.

- A narrow definition of torture by authorities might impede access to international protection.

*) Department of Medical Education, Icahn School of Medicine at Mount Sinai, 1 Gustave L. Levy Place, New York, NY, 10029, USA Correspondence to: kimberly.baranowski@mssm.edu

${ }^{\star \star}$ ) Department of Medical Education, Icahn

School of Medicine at Mount Sinai, 1 Gustave

L. Levy Place, New York, NY, 10029, USA

Correspondence to: eileen.wang@icahn.mssm.edu

$\star \star \star \star)$ Department of Medical Education, Icahn

School of Medicine at Mount Sinai, 1 Gustave

L. Levy Place, New York, NY, 10029, USA

Correspondence to: megan.dandrea@icahn.mssm.edu

$\star \star \star \star)$ Departments of Emergency Medicine and Medical Education, Icahn School of Medicine at Mount Sinai, 1 Gustave L. Levy Place, New York, NY, 10029, USA

Correspondence to: elizabeth.singer@mssm.edu

\begin{abstract}
Introduction: Every year, thousands of women flee gender-based violence in Honduras, El Salvador, and Guatemala (sometimes collectively referred to as the Northern Triangle) in an attempt to seek asylum in the United States. Once in the United States, their legal teams may refer them for a psychological evaluation as part of their application for asylum. Licensed clinicians conduct in-depth interviews in order to document the psychological impact of the reported human rights violations. Method: Using archival de-identified data from a human rights program, this study gathered the experiences of gender-based violence reported by 70 asylum-seeking women from Honduras, El Salvador, and Guatemala who participated in pro bono psychological evaluation. Descriptive data were analyzed using a modified consensual qualitative research (CQR-M) method. Results: These asylum seekers reported exposure to systemic violence, including severe intimate partner violence, as well as physical and sexual assaults, and threats of death by organized criminal groups in their communities. Additionally, over a third of women reported experiences of violence during their migration. The majority of asylum seekers endorsed symptoms associated with anxiety $(80 \%)$ and depression (91\%), as well as trauma and
\end{abstract}


stressor-related symptoms (80\%). Discussion: The results of this study elucidate the many forms of gender-based violence experienced by women in this region, the physical and psychological sequelae of this persecution, and the systemic forces that prevent them from remaining in their countries of origin. The research results also highlight the potential impact of trauma on the women's ability to testify effectively during asylum legal hearings, elucidate factors that may contribute to their resilience in light of the human rights violations they survived, and suggest implications for clinical practice.

Keywords: Gender-based violence, Central America, human rights, refugees, United States.

\section{Introduction}

Women constitute an increasing number of asylum seekers fleeing escalating violence in Honduras, El Salvador, and Guatemala, and in 2016 the largest number of defensive asylum applications filed with immigration courts in the United States were from these countries, representing nearly 40,000 applications (Mossaad \& Baugh, 2018). Although each of these nations has unique historical, social, political, and cultural realities, women are collectively "fleeing epidemic levels of violence, including genderbased violence" from this region (United Nations High Commissioner for Refugees [UNHCR], 2015, p. 2). The term gender is used to indicate "the social characteristics assigned to men and women," and genderbased violence (GBV) describes "violence that is directed against a person on the basis of gender or sex" (UNHCR, 2003, p. 11).

GBV encompasses a range of abuses including emotional, psychological, physical, and sexual violence, as well as socio-economic violence characterized by discrimination, exclusionary practices, and unresponsive legal processes (UNHCR, 2003). Survivors of GBV may experience a range of acute and chronic physical health outcomes including, but not limited to, physical injury, infection, disease, unwanted pregnancy, and miscarriage. In addition, this violence may lead to symptoms associated with depression, anxiety, trauma- and stressor-related disorders, and suicidality. GBV may also culminate in femicide, or the intentional murder of women (World Health Organization [WHO], 2012). Intimate partner violence (IPV) includes "any behavior within an intimate relationship that causes physical, psychological, or sexual harm" and is one of the most common forms of GBV (WHO, 2012, p. 1). IPV is associated with a range of societal factors including decreased economic and social status of women, absence of women's civil rights, and limited legal protections for violence in marriage (WHO, 2012). Such abuse in Honduras, Guatemala, and El Salvador is largely unchecked by government and law enforcement, and women often decide not to report these incidents, believing that their responses would be futile or because members of law enforcement are a direct source of harm (UNHCR, 2015). Moreover, these nations experience the highest rates of women murdered among countries not at war (Folkerts, BurgiPalomino, \& Buckhout, 2016), and El Salvador had the greatest number of gendermotivated killings in the world in 2013 (Parish, 2017).

\section{Gender-based violence as torture}

Nations that fail to protect women and girls from violence that causes severe physical or psychological harm are in breach of their commitments under the Convention Against Torture and Other Cruel, Inhuman or Degrading Treatment or Punishment 
(United Nations General Assembly, 1984) which prohibits intentional acts that cause severe pain or suffering, for purposes including, but not limited to: intimidation, coercion, and discrimination by or with the acquiescence of public officials or others acting in an official capacity. The impact of GBV, torture, or other unaddressed human rights violations is significant; many of these experiences necessitate that survivors flee, having been unable to secure protection in their home countries (Hiskey, Cordova, Orces, \& Malone, 2016). Some research has documented the exposure to trauma and experiences of resilience among Central American women in the aftermath of civil wars of the 1970s and 1980s, while other studies have demonstrated increased risk of GBV and IPV in conflict and displacement settings (Stark \& Ager, 2011; Wirtz et al., 2014). More recently, there have been studies utilizing interviews to understand the experiences of women who have fled violence in Honduras, El Salvador, and Guatemala living in Mexico (Schmidt \& Buechler, 2017) and women from Central America, South America, and Mexico living in the United States (Kaltman, Hurtado de Mendoza, Gonzales, Serrano, \& Guarnaccia, 2011).

Another method to capture these women's experiences is through the analysis of physical and/or psychological evidence of human rights violations documented by clinicians as part of the asylum process (Physicians for Human Rights, 2012). Such assessments represent a unique opportunity to investigate the effects of persecution and present information to adjudicators in immigration court (Meffert, Musalo, McNiel, \& Binder, 2010; Prabhu \& Baranoski, 2012). These evaluations also may have therapeutic value due to the clinician's empathic and supportive stance during the assessment (Gangsei \& Deutsch, 2007).
Although men, boys, transgender, and gender-expansive individuals are also exposed to violence in this region (Médecins Sans Frontières, 2017), the purpose of this study was to identify how the experiences of women asylum seekers may be understood through the lens of GBV and the criteria for international protection. Secondary aims were to elucidate the physical and psychological sequelae, as well as migration and immigration detention experiences, of these women in order to inform practice guidelines for clinicians and to increase our understanding of how GBV may affect testimony in the context of application for asylum.

\section{Method}

\section{Sample and procedure}

We undertook a retrospective, qualitative chart review of medico-legal affidavits using a convenience sample of women who fled GBV in Honduras, El Salvador, or Guatemala and who sought pro bono forensic psychological evaluations from a human rights program as part of their application for asylum. The evaluations were conducted by licensed and trained clinicians who followed the Istanbul Protocol guidelines (UNHCR, 2004). The evaluation process included access to emergency medical or psychiatric services if needed, and all clients were offered linkages to continuity medical and social services. This study was approved by the program's Institutional Review Board and all records were fully de-identified to protect personal health information.

A total of 70 cases between 2014 and 2018 were eligible for analysis. All of the evaluators documented evidence consistent with the women's accounts of ill treatment in their countries of origin. The asylum seekers ranged in age from 18 to 55 years 
$(M=29.4 ; S D=6.5)$. They identified as Salvadoran $(n=24,34 \%)$, Guatemalan $(n=$ $15,21 \%)$, and Honduran $(n=31,44 \%)$. The women identified as Latina $(n=60,86 \%)$, Garifuna $(n=4,6 \%)$, and members of other indigenous communities $(n=6,8 \%)$, and as heterosexual $(n=68,97 \%)$ and lesbian $(n=$ $2,3 \%)$. They reported no formal education $(n=5,7 \%)$, primary school education $(n=$ $31,44 \%$ ), some high school or high school diplomas ( $n=31,44 \%$ ), and some college or college degrees $(n=3,4 \%)$. The evaluations were conducted in both community ( $n=$ $47,67 \%)$ and detention center $(n=23$, $33 \%$ ) settings. All of the women were fluent speakers of Spanish and interpreters were used during the evaluation when appropriate.

\section{Data analysis}

Modified consensual qualitative research (CQR-M) is a method to systematically analyze large samples of qualitative data (Spangler, Liu, \& Hill, 2012). The research team consisted of three trained coders: one psychologist and two research assistants. Together, the team worked to identify common participant experiences through the creation of domains that organized the data into general themes (Thompson, Vivino, \& Hill, 1997) and then categories which provided greater detail (Ladany, Thompson, \& Hill, 2012). Throughout the analysis, the team ensured consistency and limited bias by arguing discrepant codes to consensus. After the initial 60 cases were analyzed, the final ten cases were coded and did not yield any new domains or categories; therefore, the team established a "stability of findings" and determined that the data had been appropriately analyzed (Hill, Thompson, \& Williams, 1997). Finally, the team assigned frequencies to indicate the level of representativeness of the codes given the study sample. A domain or category was labeled "general" if it represented almost all of the cases (66-70 cases), "typical" if it represented more than half of the sample (3665 cases), and "variant" if it represented less than half of the cases (5-35 cases) (Ladany, Thompson, \& Hill, 2012). Categories with four or fewer cases ( $5 \%$ of the total cases) were determined to not be representative of our sample and are not reported.

\section{Results}

The CQR-M process yielded seven domains that organized the data into broad topic areas. A total of 30 categories were added to these domains, which further described the common experiences across the 70 cases.

Table 1 contains the domains and categories, as well as their accompanying frequencies.

\section{Education and vocation}

Many of the women cited sociocultural forces including poverty and traditional gender roles as shaping their access to educational and occupational opportunities. They reported they: (a) were forced to leave school early; and (b) experienced child labor.

Forced to leave school early: Most women disclosed that although they wanted to continue to attend classes and planned for professional careers, they were unable to complete their educations. There were some asylum seekers who had graduated high school or attended college, however many others left school at an early age due to a variety of factors, including the inability to pay school fees, or because they became pregnant and were required to care for their children.

Experience of child labor: Most of the women commented that they needed to work at a young age in order to help support their families. They stated that 
Table 1: Domains, Categories, and Frequencies of Asylum Seekers'Experiences

\section{Domain}

Category and Frequency

$\begin{array}{lll}\begin{array}{l}\text { Honduras } \\ (n=31)\end{array} & \begin{array}{l}\text { El Salvador } \\ (n=24)\end{array} & \begin{array}{l}\text { Guatemala } \\ (n=15)\end{array}\end{array}$

\section{Education and Vocation}

Forced to Leave School Early: Typical $(63 \% ; n=44)$

Experience of Child Labor: Variant $(37 \% ; n=26)$

\section{Experiences of Persecution}

Gang Violence: Typical $(67 \% ; n=47)$

Intimate Partner Violence: Typical $(63 \% ; n=44)$

Family-Based Violence: Variant $(37 \% ; n=26)$

\section{Forms of Violence}

Sexual Assault: Typical $(84 \% ; n=59)$

Threatened Death: Typical $(83 \% ; n=58)$

Physical Assault: Typical $(81 \% ; n=57)$

Verbal Assault: Typical $(71 \% ; n=50)$

Control: Typical $(57 \% ; n=40)$

Harm to Minor Child: Variant $(43 \% ; n=30)$

Extortion: Variant $(34 \% ; n=24)$

Threats of Harm to Family: Variant (33\%; $n=23$ )

Threats of Harm to Minor Child: Variant ( $31 \% ; n=22)$

Harm to Family: Variant $(23 \% ; n=16)$

\section{Physical Sequelae of Persecution}

Laceration or Puncture Wound: Variant $(40 \% ; n=28)$

Blunt Trauma to Head: Variant ( $39 \% ; n=27)$

Blunt Trauma to Body: Variant $(36 \% ; n=25)$

Gynecological Injury: Variant $(31 \% ; n=22)$

Burns: Variant $(16 \% ; n=11)$

\section{Psychological Sequelae of Persecution}

Depression Sxs: Typical $(91 \% ; n=64)$

Anxiety Sxs: Typical $(80 \% ; n=56)$

Trauma-, Stressor-related Sxs: Typical $(80 \% ; n=56)$

Past Suicidal Ideation: Variant $(47 \% ; n=33)$

Continued Fears for Family: Variant $(40 \% ; n=28)$

\section{Migration Experiences}

Traveled with Child: Typical $(74 \% ; n=52)$

Detention: Typical $(61 \% ; n=43)$

Internal Displacement: Typical $(54 \% ; n=38)$

Violence During Migration: Variant $(37 \% ; n=26)$

Hazardous Conditions: Variant $(29 \% ; n=20)$

Resilience: Typical $(73 \% ; n=51)$
18

21

13

10

13

7

6

$21 \quad 8$

$13 \quad 10$

$6 \quad 7$

$\begin{array}{lll}26 & 20 & 13 \\ 28 & 19 & 11 \\ 26 & 17 & 14 \\ 21 & 17 & 12 \\ 14 & 17 & 9 \\ 15 & 10 & 5 \\ 8 & 10 & 6 \\ 6 & 12 & 5 \\ 11 & 6 & 5 \\ 7 & 6 & 3\end{array}$

$\begin{array}{lll}16 & 8 & 4 \\ 15 & 7 & 5 \\ 10 & 7 & 8 \\ 12 & 6 & 4 \\ 6 & 4 & 1\end{array}$


they harvested and distributed agricultural products; sold homemade or massproduced food items; worked for local businesses; cooked and maintained the family home; and/or cared for siblings and relatives. Some asylum seekers also reported workplace exploitation including long hours and wage theft, while others explained they were solely responsible for maintaining the home, preparing meals, and raising the children.

\section{Experiences of persecution}

The women reported that they experienced: (a) family-based violence; (b) intimate partner violence; and (c) gang violence. The specific acts of violence they experienced are highlighted in the third domain.

Family-based violence: Many of the women recalled that they experienced harm in their families of origin. They reported witnessing domestic violence while living with their parents or extended family, experiencing physical forms of punishment as children that exceeded what they considered to be appropriate discipline, and surviving sexual abuse by fathers, uncles, and cousins.

Intimate partner violence: It was common for the women to report experiences of abuse in their intimate relationships, and much of their experiences reflected elements of "power and control" common to IPV (Domestic Abuse Intervention Project, n.d.). They often indicated that the onset of IPV coincided with their pregnancies and increased in frequency and severity over time. Attempts by the women's families and/or in-laws to intervene were ineffective in securing their safety and asylum seekers noted that IPV was normalized in their communities with the expectation that women "fulfill their roles" by remaining in their relationships.
Gang violence: The majority of women stated that they experienced violence associated with armed criminal groups that committed crimes with impunity, resulting in fears for their own safety, as well as concerns for their families. Most of the women reported that members of Mara Salvatrucha (MS-13) and/or Barrio 18 controlled their villages, cities, and countries, and that the gangs wielded their power through the collection of "renta" (protection tax), threats, kidnapping, sexual assault, forced recruitment, bribes, and murder.

\section{Forms of violence}

The asylum seekers noted that, as women, they were especially vulnerable to violence in their countries of origin including: (a) verbal assault; (b) physical assault; (c) sexual assault; (d) threatened death; (e) control; (f) extortion; (g) harm and threats of harm to minor child(ren); and (h) harm or threats of harm to family.

Verbal assault: The women disclosed experiences of chronic verbal abuse including being called "basura" (trash) and "perra" (dog), as well as other gender-based slurs. The asylum seekers also revealed that they were subjected to insults that referenced their real or perceived indigenous backgrounds and identities such as being told to "go back to the mountains."

Physical assault: The women reported that they survived a range of physical violence. One asylum seeker commented that her partner "would throw anything he had in his hand" at her. During the course of the assaults, women also stated that they were "slapped and pushed," had their "hair grabbed and pulled," and were "choked," "punched," "kicked," "burned," "stabbed," and "shot."

Sexual assault: Many of the asylum seekers discussed experiences of sexual violence. 
They reported they were forced to perform non-consensual sexual acts and were raped in the context of their intimate partnerships. Other women stated they experienced sexual assault by family members, neighbors, and members of the community, while still others endured kidnapping and repeated sexual assaults associated with "gang rapes."

Threatened death: The women described experiencing death threats in the form of text and hand written messages, phone calls, and face-to-face confrontations. They often reported that they were menaced by knives, machetes, and firearms. In addition, the women also explained that they feared they would be killed during the course of physical and sexual assaults.

Control: The asylum seekers reported a range of experiences of disempowerment associated with GBV, including experiences of economic abuse which often rendered them unable to work to support themselves and their children, because their partners prohibited their employment or because they had to hide from gang members. They indicated that their partners prevented them from leaving their homes, denied them access to a cell phone or control over money, and dictated what clothing and make-up they could wear. When their partners also had ties to organized crime, the women recalled that the gangs aided in the intimidation by engaging in stalking and harassment.

Extortion: The women reported that the gangs in their communities extorted money in the form of "renta" or taxes and that if they owned businesses, were known to have steady work, or had family in the United States presumed to be providing remittances, gang members forced them to pay a portion of their incomes and made death threats if they did not comply.

Harm and threats of harm to minor child(ren): The women indicated that the perpetrators of GBV threatened harm or inflicted injury on their children, which were often cited as the reasons the women sought safety in the United States. In addition, the women discussed their fears that their children would "disappear" or would be "forced to join the gangs."

Harm or threats of harm to family: Lastly, the women noted that their families were targeted with both threats of harm and actual injury. Some women also revealed that their relatives were "robbed," "beaten," "kidnapped," and "murdered."

\section{Physical sequelae of persecution}

The women reported sustaining physical injuries as a result of the violence reported above. Many of the asylum seekers stated that they experienced bruising, welts, and burns during physical assaults, in addition to blunt head trauma, broken teeth, or loss of consciousness. In some cases, they described long term sequelae of these head injuries and post-concussion syndromes, including dizziness, headache, neuropsychiatric symptoms, and/or cognitive impairment for a period of time after the assaults. A few women also indicated that they sustained penetrating trauma from being stabbed or shot. Others disclosed being kicked and punched in their abdomens during pregnancy which in some cases led to spontaneous miscarriages. As expected, the women who reported experiencing rape often described injuries to their genitourinary systems including bleeding and pain. Lastly, a few asylum seekers disclosed experiencing forced sterilization. 


\section{Psychological sequelae of persecution}

The women endorsed psychological distress related to their experiences of persecution including symptoms associated with: (a) anxiety and (b) depression; as well as (c) trauma and stressor-related symptoms and (d) past suicidal ideation. The women also discussed (e) continued fears for family.

Anxiety symptoms: The asylum seekers endorsed symptoms related to anxiety, including feeling fearful, worried, nervous, restless, and tense. In some cases, their distress was directly related to a lack of safety following an experience of violence; for example, one woman commented "my door is made of tin, anyone could easily break in."

Depression symptoms: Almost all of the women reported symptoms associated with depression including low mood and diminished interest in activities. They also disclosed problems with memory, attention and concentration, which negatively impacted their functioning, as well as tearfulness, with one woman noting, "I cry easily when alone." In some cases, their distress was described in more spiritual terms, as exemplified by one woman's comment, "My soul hurts."

\section{Trauma and stressor-related symptoms:}

The majority of the asylum seekers reported trauma and stressor-related symptoms. They described a range of intrusion symptoms including being "flooded by memories," as well as nightmares of being chased or attacked. Symptoms also included cued physiological distress when reminded of the trauma. For example, one woman noted, "I sweat, I tremble, I become fidgety," while others reported experiencing a "racing heart." They reported avoidance of external reminders of the traumas and endorsed alterations in cognition and mood. In addition, some women described experiencing increased arousal and reactivity, including sleep disturbances. Others indicated that the violence "changed" them and reported feeling ashamed, embarrassed, and humiliated by their experiences.

Past suicidal ideation: Some of the women reported past thoughts of killing themselves following their experiences of GBV. They also reported that their thoughts of suicide increased in response to fears of deportation and the belief that they would be murdered if forced to return to their countries of origin. In many of the cases, women cited their families, children, and faith as protective factors against self-harm, as well as their hopes for building a secure home in the United States.

Continued fears for family: The asylum seekers also noted that they worried for their family members who remained in their countries of origin. One woman commented, "I am worried for my children, what will happen to them?" while another remarked that the gangs "kill people who defy them." Some women described continued threats, and others expressed concern that their flight to the United States made their families especially vulnerable to reprisals by gang members.

\section{Migration experiences}

The women described migration experiences characterized by: (a) internal displacement; (b) travel with their child(ren); (c) hazardous conditions; (d) violence; and (e) detention once in the United States.

Internal displacement: The women explained that they initially attempted to hide within their countries of origin. However, because their governments and law enforcement officials were unable and/or unwilling 
to protect women from GBV, their experiences of violence continued. They described the police as "absent," "corrupt," and "not powerful enough" to effectively address IPV or combat organized crime. Others feared retribution, because "the gangs know if you go to the police and they will kill your whole family."

Traveled with their child(ren): Almost all of the women fled with at least one of their children. Notably, the asylum seekers forced to leave children behind reported distress associated with having to decide which children to take with them. They often cited their inability to secure the money necessary to bring all of their children as the primary reason they had to leave some in the care of family. Some were motivated to shield their girls from GBV, as exemplified by the statement, "I brought my daughter, [because] I did not want this to happen to her." Others made the painful decision to take their youngest children, because they were still "small enough to be carried" or had to leave infants too fragile to survive the trip.

Hazardous conditions: Some women reported they were forced to travel by cargo train or hide in vehicle storage compartments during their flight to the United States. One woman explained, "We couldn't see light, just darkness," and another recalled, "I thought we would suffocate.” Many women reported little access to food or water and indicated they went hungry to ensure their children were fed. As they approached the United States/Mexico border, they walked through the desert and were forced to sleep outside exposed to the elements. Several women commented that other migrants displayed generosity in light of these dangers and assisted them during their journeys.
Violence during migration: They reported hearing that women were often targeted with violence during the journey to the United States. One asylum seeker noted, "I heard stories about the Zetas and Narcos, they abused women," and another disclosed she "dressed as a man during the trip" to remain safe. The women explained that coyotes, or human smugglers, transported them across borders and described experiences of theft, extortion, sexual assault, and/or threatened abduction or death during their migration.

Detention: Most of the women were initially detained in the United States by Border Patrol agents and were later transferred to Immigration and Customs Enforcement (ICE) custody. The asylum seekers whose children were taken from them by officials reported extreme distress due to these forced separations. They described being detained at the border in "hieleras" (ice boxes), concrete cells maintained at uncomfortably cold temperatures, and in "perreras" (kennels), chain-link fenced enclosures. Some of the asylum seekers were released to the community after a few days, while others were transferred to immigration detention centers. One asylum seeker reflected on the impact of detention by stating, "We don't have our liberty, and that makes us sad."

Women expressed worry related to their immigration proceedings; for example, one woman felt "unprepared to talk," and another commented, "I am scared of them, I am afraid they won't believe me." Some reported concerns regarding their ability to testify effectively, such as, "When I feel nervous, I have memory problems." Others revealed confusion associated with receiving negative credible fear decisions, for example, "Am I missing something? Do I need more words so they will understand?" 
Not surprisingly, the women disclosed fears related to the dangers they would face if forcibly returned to their countries of origin. One woman explained, "I feel very fearful, I know what is waiting for me in my country," and another observed, "Now that they know I have escaped, if I return, I am dead."

\section{$\underline{\text { Resilience }}$}

Despite the wide range of human rights abuses these women reported, they also possess a series of factors related to resilience. Many women stated that they found comfort and "strength" in their religious beliefs and focused on their families in order to cope with the violence they survived. Given this, forced separation from loved ones was an oft-cited major stressor. The asylum seekers also ascribed their tenacity to temperamental qualities, such as remaining hopeful: "I have always been a positive woman, I keep going" and "I have to adapt to my new life, everything is different, but I take it as an education." Lastly, some women revealed that their experiences led to a commitment to help others: "The support people have shown me, I am going to pay that back" and "I want people to know that we have to keep fighting, we cannot give up."

\section{Discussion}

This study describes the multi-pronged nature of human rights violations that women seeking asylum from Honduras, El Salvador, and Guatemala have encountered; physical and psychological impact of these experiences; threats to their families and children; and systemic forces that compel them to flee their countries. Their histories further highlight how far-reaching and deeply entrenched violence toward women can be in this region, as well as the perils these women may encounter during migration and postmigration, once inside the United States.
The women in our sample presented with current symptoms associated with anxiety (80\%) and depression (91\%), as well as trauma and stressor-related symptoms $(80 \%)$, and past suicidal ideation $(47 \%)$. While these symptoms were not always associated with formal clinical diagnoses, they correlated with significant distress in many of the cases included in this study. Furthermore, these asylum seekers reported sustaining both blunt $(67 \%)$ and penetrating $(40 \%)$ trauma during the course of GBV. Given these findings, clinicians should assess for possible exposure to GBV, prioritize mental health screening when caring for this population, and provide culturally-responsive, linguisticallyappropriate, and trauma-informed services. In addition, IPV can begin or escalate in pregnancy and is associated with adverse outcomes for both the mother and infant (Cook \& Bewley 2008; Bailey 2010). Therefore, increasing access to care for pregnant women and their children can ultimately decrease maternal-fetal-child morbidity and mortality. Lastly, given the resilience demonstrated by the women in this study, clinicians should support factors that increase adaptive functioning and integrate strengths-based approaches into their practices.

The mental health correlates of GBV have implications for asylum seekers' abilities to effectively testify during their credible fear interviews and immigration hearings (Cohen, 2001). Consequently, an assessment of the psychological impact of their experiences of trauma may be essential (Lustig et al., 2008; Scruggs, Guetterman, Meyer, VanArtsdalen, \& Heisler, 2016). The asylum seekers in this study reported difficulties with memory, attention, and concentration which are associated with depression, anxiety, and trauma and 
stressor-related symptoms. Similarly, the asylum-seeking process is replete with ongoing fears, and increased stress can lead to higher levels of endogenous cortisol that may decrease memory performance (Backhaus et al., 2006). These sequelae may impact the consistency, quality, and quantity of women's testimony (Meffert et al., 2010), and the mental health correlates of trauma should be acknowledged during immigration proceedings and subsequent determinations of credibility.

Furthermore, this study highlights women's reports of the ways GBV can be sanctioned by socio-cultural norms and political structures in Honduras, El Salvador, and Guatemala, including gender inequality and the acquiescence of law enforcement to organized crime. Given the recent legal and political debates over immigration policies related to GBV and gang-related violence in the United States, it is important for asylum adjudicators to understand how country conditions prevent these survivors from finding secure refuge in their countries of origin (Rodríguez Serna, 2016).

A few potential study limitations exist, including that all women in this sample originated from Honduras, El Salvador, or Guatemala, and these experiences of GBV and their sequelae may not be generalizable to women from other nations in the context of their unique socio-cultural-political histories. Future studies should, therefore, investigate the experiences of asylum seekers who have survived GBV in other regions of the world. In addition, the convenience sample and retrospective nature of this study limited the data available for analysis. Finally, this study does not address violence in asylum seekers who identify as members of LGBTQ communities, as our sample size was limited for these groups. However, persecution based upon sexual orientation and gender identity is acknowledged in this sector of asylum seekers (Pérez-Sales \& Zraly, 2018).

\section{Conclusion}

This study captures women's experiences of systemic violence in a region without effective intervention by law enforcement and government. Article 33 of the U.N. 1951 Refugee Convention and Protocol prohibits non-refoulement, or the return of refugees to a country where their lives or freedoms would be endangered (UN General Assembly, 1951). The results of this study suggest that women fleeing GBV in El Salvador, Guatemala, and Honduras meet criteria as survivors of torture and require international protection. Their health and general wellbeing would benefit if they were granted asylum.

\section{References}

Backhaus J., Junghanns K., Born J., Hohaus K., Faasch F., \& Hohagen F. (2006). Impaired declarative memory consolidation during sleep in patients with primary insomnia: Influence of sleep architecture and nocturnal cortisol release. Biological Psychiatry, 60(12), 1324-1330. doi: 10. 1016/j.biopsych.2006.03.051.

Bailey, B. A. (2010). Partner violence during pregnancy: prevalence, effects, screening, and management. International fournal of Women's Health, 2, 183-187. doi: 10.2147/ijwh.s8632.

Cohen J. (2001). Questions of credibility: Omissions, discrepancies and errors of recall in the testimony of asylum seekers. International Fournal of Refugee Law, 13(3), 293-309. doi:10.1093/ijrl/13.3.293.

Cook J., \& Bewley S. (2008). Acknowledging a persistent truth: Domestic violence in pregnancy. Fournal of the Royal Society of Medicine, 101(7), 358-363. doi: 10.1258/jrsm.2008.080002

Domestic Abuse Intervention Project. (n.d.). Power and control wheel. Retrieved from www.ncdsv.org/images/ PowerControlwheelNOSHADING.pdf

Folkerts, L., Burgi-Palomino, D., \& Buckhout, E. (2016). A look at the Northern Triangle of Central America in 2016: Sustained violence and displacement. Latin America Working Group: 
Action at Home for Just Policies Abroad. Retrieved from www.lawg.org/a-look-at-thenorthern-triangle-of-central-america-in-2016sustained-violence-and-displacement/

Gangsei, D., \& Deutsch, A. C. (2007).

Psychological evaluation of asylum seekers as a therapeutic process. Torture fournal, 17(2), 79-87. Retrieved from irct.org/assets/ uploads/1018-8185_2007-2_79-87.pdf.

Hill, C. E., Thompson, B. J., \& Williams, E. N. (1997). A guide to conducting consensual qualitative research. The Counseling Psychologist, 25, 517-572.

Hiskey, J., Cordova, A., Orces, D., \& Malone, M. F. (2016). Understanding the Central American refugee crisis: Why they are fleeing and how U.S. policies are failing to deter them. American Immigration Council. Retrieved from www. americanimmigrationcouncil.org/sites/default/ fils/research/understanding_the_central_ american_refugee_crisis.pdf

Kaltman, S., Hurtado de Mendoza, A., Gonzales, F. A., Serrano, A., \& Guarnaccia, P. J. (2011). Contextualizing the trauma experience of women immigrants from Central America, South America, and Mexico. Fournal of Traumatic Stress, 24(6), 635-642. doi: 10.1002/jts.20698

Ladany, N., Thompson, B. J., \& Hill, C. E. (2012). Cross-analysis. In C. E. Hill (Ed.), Consensual qualitative research: A practical guide for investigating social science phenomena (pp. 117-134). Washington, DC: American Psychological Association.

Lustig, S. L., Kureshi, S., Delucchi, K. L., Iacopino, V., \& Morse, S. C. (2008). Asylum grant rates following medical evaluations of maltreatment among political asylum applicants in the United States. Journal of Immigrant Minority Health, 10, 7-15. doi: 10.1007/s10903-007-9056-8.

Médecins Sans Frontières. (2017, May). Forced to flee Central America's Northern Triangle: A neglected humanitarian crisis. Retrieved from www.msf. $\mathrm{org} / \mathrm{sites} / \mathrm{msf}$.org/files/msf_forced-to-flee-centralamericas-northern-triangle_e.pdf

Meffert, S. M., Musalo, K., McNiel, D. E., \& Binder, R. L. (2010). The role of mental health professionals in political asylum processing. The Fournal of the American Academy of Psychiatry and the Law, 38, 479-89. Retrieved from www. repository.uchastings.edu/cgi/viewcontent.cgi?arti cle $=2155 \&$ context $=$ faculty_scholarship.

Mossaad, N., \& Baugh, R. (2018). Refugees and asylees: 2016. Annual Flow Report, Department of Homeland Security, Office of Immigration Statistics. Retrieved from www.dhs.gov/ sites/default/files/publications/Refugees_
Asylees_2016.pdf

Parish, A. (2017, September). Gender-based violence against women: Both cause for migration and risk along the journey. Migration Policy Institute. Retrieved from www.migrationpolicy. org/article/gender-based-violence-against-womenboth-cause-migration-and-risk-along-journey

Pérez-Sales, P., \& Zraly, M. (2018). From sexualized torture and gender-based torture to genderized torture: The urgent need for a conceptual evolution. Torture fournal, 28(3), 113. doi: $10.7146 /$ torture.v28i3.111179.

Physicians for Human Rights. (2012). Examining asylum seekers: $A$ health professional's guide to medical and psychological evaluations of torture. Boston, MA: Author.

Prabhu, M., \& Baranoski, M. (2012). Forensic mental health professionals in the immigration process. Psychiatric Clinics of North America, 35(4), 929946. doi: 10.1016/j.psc.2012.08.012

Rodríguez Serna, N. (2016). Fleeing cartels and maras: International protection considerations and profiles from the Northern Triangle. International fournal of Refugee Law, 28(1), 2554. doi: 10.1093/ijrl/eev061

Schmidt, L., \& Buechler, S. (2017). «I risk everything because I have already lost everything:" Central American female migrants speak out on the migrant trail in Oaxaca, Mexico. Fournal of Latin American Geography, 16(1), 139-164. doi:10.1353/lag.2017.0012.

Scruggs, E., Guetterman, T. C., Meyer, A. C., VanArtsdalen, J., \& Heisler, M. (2016). “An absolutely necessary piece:” A qualitative study of legal perspectives on medical affidavits in the asylum process. Fournal of Forensic and Legal Medicine, 44, 72-78. doi:10.1016/j. jflm.2016.09.002

Spangler, P. T., Liu, J., \& Hill, C. E. (2012). Consensual qualitative research for simple qualitative data: An introduction to CQR-M. In C.E. Hill (Ed.), Consensual qualitative research: A practical resource for investigating social science phenomena (pp. 269-283). Washington, DC: American Psychological Association.

Stark, L., \& Ager, A. (2011). A systematic review of prevalence studies of gender-based violence in complex emergencies. Trauma, Violence, E Abuse, 12(3), 127-134. doi: $10.1177 / 1524838011404252$.

Thompson, B. J., Vivino, B. L., \& Hill, C. E. (2012). Coding the data: Domains and core ideas. In C.E. Hill (Ed.), Consensual qualitative research: A practical resource for investigating social science phenomena (pp. 103-116). Washington, DC: 
American Psychological Association.

UN General Assembly. (1951). Convention relating to the status of refugees. United Nations, Treaties Series. Retrieved from www.unhcr.org/enus/3b66c2aa 10

United Nations General Assembly. (1984). Convention against torture and other cruel, inhuman or degrading treatment or punishment. United Nations, Treaty Series. Retrieved from www.ohchr.org/en/ professionalinterest/pages/cat.aspx

United Nations High Commissioner for Refugees. (May, 2003). Sexual and gender-based violence against refugees, returnees and internally displaced persons: Guidelines for prevention and response. Retrieved from www.unicef.org/emerg/files/ gl_sgbv03.pdf.

United Nations High Commissioner for Human Rights. (2004). Istanbul protocol:

Manual on the effective investigation and documentation of torture and other cruel, inhuman or degrading treatment or punishment. Geneva, Switzerland: Author.

United Nations High Commissioner for Refugees. (2015, October). Women on the run. Retrieved from www.unhcr.org/publications/ operations/5630f24c6/women-run.html

Wirtz, A. L., Pham, K., Glass, N., Loochkartt, S., Kidane, T., Cuspoca, D., ... Vu, A. (2014).

Gender-based violence in conflict and displacement: Qualitative findings from displaced women in Colombia. Conflict and Health, 8(1), 10. doi: 10.1186/1752-1505-8-10.

World Health Organization. (2012). Understanding and addressing violence against women. Retrieved from www.apps.who.int/iris/bitstream/ handle/10665/77421/WHO_RHR_12.38_eng. pdf?sequence $=1$ \&isAllowed $=\mathrm{y}$. 